\title{
LA MUTACIÓN CONSTITUCIONAL DEL PRINCIPIO DE NO INTERVENCIÓN
}

\author{
CONSTITUTIONAL MUTATION OF NON-INTERVENTION \\ PRINCIPLE
}

\author{
José Luis LEAL SANABRIA* \\ Carlos CERDA DueÑAS**
}

\begin{abstract}
RESUMEN: Las modificaciones constitucionales se realizan a través de reformas y mutaciones, estas últimas entendidas como un proceso informal de alteración de la Constitución que implica la modificación del sentido de la norma, aunque el texto constitucional continúe siendo el mismo, y se originan debido a la práctica parlamentaria, por la administración y por la jurisdicción. Este artículo plantea que el principio de no intervención que debe seguir el Ejecutivo en la conducción de la política exterior, según lo establece la fracción X del artículo 89 constitucional, se ha modificado en su interpretación, debido, en gran parte, a la práctica política como producto de los cambios que han impactado a dicho principio, tanto en el nivel interno como en el orden internacional, por lo que se pretende demostrar que se está frente a una mutación constitucional.

Palabras clave: Constitución mexicana, reforma, mutación constitucional, principio de no intervención, política exterior.
\end{abstract}

ABSTRACT: Constitutional amendments are made through reforms and mutations, understood the latter as an informal process of alteration of the Constitution, which involves the modification of the sense of the legal precept, although the constitutional text remains the same. Mutations' causes are parliamentary, administrative or political, and jurisdictional practice. This article proposes that the principle of non-intervention that has to be complied by the Executive when performs foreign policy, according to the section X of article 89 of the Mexican Constitution, has changed in its interpretation due, in large part, to political practice and this is a result of changes in internal level and international order. The article intends to demonstrate that it is facing a constitutional mutation.

Descriptors: Mexican Constitution, amendment, constitutional mutation, non-intervention principle, foreign policy.

* Doctor en derecho; maestro emérito por la Universidad de Guadalajara; especialista en derecho constitucional.

** Abogado por la Universidad de Guadalajara y doctor en derecho por la Universidad de Buenos Aires; profesor del Tecnológico de Monterrey, Campus Guadalajara. 


\section{INTRODUCCIÓN}

Durante largo tiempo, gran parte del prestigio de la actuación internacional de México descansó en el principio de no intervención. Nuestro país esbozaba el ejercicio de dicho principio para, por una parte, mandar el mensaje de respeto a la soberanía de sus pares frente a actos o situaciones acontecidas en éstos, por más reprobables que fueran y, por otra parte, para asumir una cómoda posición de no tener que pronunciarse y, con ello, abstenerse de tomar partido por alguna de las partes en conflicto o sobre cierta temática en particular.

Cierto es que enarbolar dicho principio hundía sus raíces en la convulsa historia del país, desde su surgimiento hasta principios del siglo XX, lo cual tendrá como punto de inflexión la invasión norteamericana al puerto de Veracruz en abril de 1914 y la internación de las tropas estadounidenses a nuestro territorio en la llamada expedición punitiva. Fue entonces que el titular del Ejecutivo, Venustiano Carranza, asume el principio de no intervención como objetivo de la política exterior mexicana, lo cual vendrán implementando todos los gobiernos subsecuentes. En 1988, el presidente Miguel de la Madrid decide incorporarlo a la Constitución, junto con otros seis principios, que desde entonces regularán la conducción de la práctica diplomática mexicana a nivel de mandato constitucional.

Sin embargo, para principios de la última década del siglo pasado, específicamente con el fin del conflicto bipolar que se conoció como la Guerra Fría, el criterio interpretativo del principio de no intervención se modificó en el entorno internacional. Simultáneamente, en el orden doméstico también se generaron muchos cambios que, necesariamente, llevaban a aplicar la nueva interpretación del principio para efectos internos, con la salvedad de que al estar establecido en la Constitución, las corrientes tradicionalistas rechazaban la adopción de una consideración diferente a la que tenía durante el largo periodo de su ejercicio y en su inserción al texto constitucional.

Jorge Carpizo señala que "los cambios y modificaciones constitucionales, que no rupturas ni violaciones, se realizan primordialmente a través de reformas y mutaciones, las cuales se integran y forman o serán parte de la propia Constitución. En consecuencia, las reformas y mutaciones que sufre la ley fundamental son su propia evolución, y como tal configuran el desarrollo de la norma, son su historia y su presente". ${ }^{1}$

1 Carpizo, Jorge, "La reforma constitucional en México. Procedimiento y realidad", 
Se debe entender a las mutaciones constitucionales como los cambios implícitos o no formales a la Constitución por medio de los cuales las disposiciones constitucionales se adaptan a la realidad, sin sufrir alteración alguna en su texto, pero sí en su contenido o comprensión. ${ }^{2}$

Este artículo argumenta que el principio de no intervención como lineamiento de política exterior establecido en la fracción X del artículo 89 constitucional ha mutado debido a la práctica política considerada por la doctrina como una de las modalidades para que se geste dicha figura jurídica. Ciertamente, aún durante el periodo de su acepción original, México no siempre se ajustó a él de forma exhaustiva, y esto podría ser apreciado como el incumplimiento de la Constitución que no se sancionó debido a la ausencia de mecanismos para adjudicar responsabilidad por tal falta de observancia. Se plantea, por lo tanto, que el cambio se ha dado en el sentido de su interpretación y no de forma derogatoria, y que ello es consecuencia de una diferente práctica política acrecentada en años recientes, inducida tanto por factores internos, como del orden global.

\section{LA MUTACIÓN CONSTITUCIONAL}

La doctrina de las mutaciones constitucionales no ha sido tratada con profundidad, no obstante la relevancia que dicha cuestión entraña. ${ }^{3} \mathrm{Si}$ consideramos al cambio, reforma, o enmienda, en la teoría del derecho constitucional, se está refiriendo a los procesos de acomodación de las normas constitucionales a la realidad, lo cual sólo puede hacerse a través de dos formas: la reforma y la mutación constitucional, que revelan, respectivamente, procesos formales y procesos informales de modificación de la Constitución. ${ }^{4}$

Boletín Mexicano de Derecho Comparado, México, UNAM, Instituto de Investigaciones Jurídicas, año XLIV, núm. 131, mayo-agosto de 2011, p. 544.

2 Benítez R., Vicente F., "Legitimidad democrática y constitucional de las modificaciones implícitas a la Constitución por parte de la jurisprudencia constitucional en Colombia”, Vniversitas, Bogotá, núm. 122, enero-junio de 2011, p. 306.

3 Uribe Arzate, Enrique y Correa Esquivel, Grisel Alejandra, "Mutaciones constitucionales y la problemática de su control en el Estado constitucional", Revista de Derecho, Barranquilla, Universidad del Norte, núm. 38, 2012, p. 198.

4 Silva, José Afonso da, "Mutaciones constitucionales", Cuestiones Constitucionales. Revista Mexicana de Derecho Constitucional, México, núm. 1, julio-diciembre de 
La doctrina considera que la reforma, en ocasiones, es un procedimiento insuficiente para adecuar la Constitución a la realidad; por ello, resalta la importancia que revisten las mutaciones constitucionales como factor de cambio en la Constitución, es decir, cuando la realidad trasciende al texto constitucional y el proceso formal de reforma se muestra insuficiente para avanzar al mismo ritmo que la realidad. ${ }^{5}$ De acuerdo con la teoría tradicional, no sería factible reconocer la existencia de modificaciones informales o mutaciones constitucionales, pues se entiende que sólo una nueva actuación del poder constituyente puede alterar las bases jurídico-políticas de la convivencia, reformando el texto constitucional y sobre todo si se trata de una Constitución rígida. Sin embargo, en la práctica las cosas no siempre suceden así. Los diversos poderes constituidos (parlamentos, gobiernos, tribunales) tienen constantemente que resolver problemas concretos a los que la Constitución o no da respuesta o la que da es manifiestamente incorrecta o impracticable a juicio de quien tiene hoy que aplicarla. ${ }^{6}$

Son los doctrinistas alemanes quienes más se han enfocado al estudio y desarrollo de este concepto, y sus principales aportaciones son de larga data, pues devienen de los últimos años del siglo XIX y los primeros del siglo XX en las obras de Paul Laband y Georg Jellinek. A este último se le atribuye la concepción del concepto de mutación a través de su libro Verfassunganderung und Verfassungwandlung: eine staatsrechtlig-politische Abhandlung, publicada en Berlín hacia 1906, y que cuenta con traducción al español bajo el título de Reforma y mutación de la Constitución. Jellinek hace referencia a las mutaciones constitucionales después de constatar que la rigidez constitucional, en muchos casos, constituye una garantía insuficiente para asegurar la fuerza normativa de la Constitución. Para Jellinek, la mutación constitucional supone el cambio operado por actos no intencionados que no alteran expresamente el texto de la Constitución. Así hace referencia a la mutación constitucional a través de la práctica parlamentaria, por la administración y por la jurisdicción. Mucho se ha refutado que Jellinek se limitara sólo a los actos no intencionados.

1999, disponible en http://biblio.juridicas.unam.mx/revista/pdf/CuestionesConstitucio nales/1/tes/tes1.pdf.

5 Uribe Arzate, Enrique y Correa Esquivel, Grisel Alejandra, op. cit., p. 208.

6 García Cuadrado, Antonio M., El ordenamiento constitucional. Un enfoque histórico y formal de la teoría de la Constitución y de las fuentes del derecho, Alicante, Club Universitarios, 2002, p. 75. 
Por su parte, Laband (en su obra Die Wandlungen der deutschen Reichsverfassung de 1895) describe cómo la Constitución del Reich es transformada sin que se accionen los mecanismos de reforma constitucional. Destaca que aunque las Constituciones son normas jurídicas en sentido estricto, la acción del Estado puede transformarlas sin necesidad de su modificación formal, pues esto se da por medio de usos y costumbres de los poderes públicos.

Sin embargo, se considera que tal vez la monografía más importante que se ha escrito sobre mutaciones constitucionales es la que elaboró el jurista taiwanés Hsü Dau Lin, ${ }^{7}$ con referencia a la Constitución de Weimar, afirmando que la mutación constitucional no es un quebrantamiento de la Constitución, ni simple regla convencional sino que es derecho. También elaboró una clasificación donde distinguía cuatro tipos de mutaciones constitucionales: a) las debidas a prácticas políticas que no se opongan formalmente a la Constitución escrita, y para cuya reglamentación no exista norma constitucional; b) las debidas a prácticas políticas en oposición abierta a preceptos constitucionales; c) las producidas por imposibilidad del ejercicio, o por desuso, de las competencias y atribuciones establecidas en la Constitución; y d) las producidas por interpretación de los términos de la Constitución, de tal modo que los preceptos obtienen un contenido distinto de aquél con el que en principio fueron pensados. ${ }^{8}$

Existen otras clasificaciones, como la que enuncia: a) mutaciones por prácticas políticas; b) mutaciones por leyes autorizadas por la misma Constitución o por otro tipo de actos jurídicos; c) mutaciones introducidas a la Constitución por vía del bloque de constitucionalidad, y d) mutaciones provenientes de interpretaciones de cláusulas constitucionales por medio de la jurisprudencia. ${ }^{9}$

Considerar a la mutación constitucional de forma lisa y llana no es una tarea sencilla, la figura tiene sus detractores y sus impulsores. Hay negadores; hay a quienes preocupa su coexistencia junto al principio de supremacía constitucional, y también están los que desearían verlas reglamentadas, en su existencia y en su forma de incorporarlas a la Constitución. Klaus Stern, jurista alemán, afirma que

7 Sánchez Urrutia, Ana Victoria, "Mutación constitucional y fuerza normativa de la Constitución. Una aproximación al origen del concepto", Revista Española de Derecho Constitucional, Madrid, año 20, núm. 58, enero-abril 2000, p. 125.

8 Silva, José Afonso da, op. cit.

9 Benítez, R. Vicente, op. cit., p. 310. 
no procede ninguna reforma de la Constitución sin reforma del texto de la Constitución y esto en virtud de la afirmación del principio fundamental de la documentabilidad y carácter expresamente visible de toda reforma de la Constitución que conduce a que el texto tiene que ser reformado, así como a entender que no se trata solamente de una variación en la enumeración del respectivo artículo, sino de que es cambiado el texto de la Ley Fundamental en su redacción y fijado de nuevo. ${ }^{10}$

Hans Kelsen considera que la interacción de la carta magna con la realidad es dudosa, puesto que, aunque el procedimiento de reforma establecido en la Constitución sea muy rígido, éste es la única forma en que debe ser renovada para ponerla de acuerdo con las necesidades de su tiempo. ${ }^{11}$

"Debido a que las mutaciones por sí mismas son un fenómeno complejo, tratar de establecer sus límites entraña una dificultad mayúscula". ${ }^{12}$ Ya el mismo Laband reparaba en "la imposibilidad de controlarlas jurídicamente", ${ }^{13}$ con todo, se admite que la figura existe, pero tiene limitaciones.

Para Jorge Carpizo ${ }^{14}$ no toda mutación es admisible; para que lo sea, debe respetar el principio de supremacía constitucional y los mismos límites que tiene el poder revisor de la Constitución. Además, debe considerarse que "el problema actual reside en la ausencia de medios de control de las mutaciones e incluso de mecanismos para su incorporación formal al texto constitucional". ${ }^{15}$

La Constitución de México — si se considera la clasificación elaborada por el británico James Bryce, quien establece la existencia de Constituciones rígidas y flexibles - definitivamente es muy rígida, no obstante que el número de enmiendas efectuadas a la misma denoten lo contrario. A ello obedece el sistema político mexicano que durante mucho tiempo contó con un sistema de partido hegemónico, y que en tiempos recientes opera en una forma de coalición legislativa, de lo cual el llamado Pacto por México (2012) es la expresión más acabada. "A pesar de que la reforma constitucional ha sido el procedimiento predominante, la figura de la mutación no ha estado ajena

10 Stern, Klaus, Derecho del Estado de la República Federal Alemana, Madrid, Centro de Estudios Constitucionales, 1987, pp. 333 y 334.

11 Kelsen, Hans, Teoría general del derecho y del Estado, México, UNAM, 1988, p. 147.

12 Uribe Arzate, Enrique y Correa Esquivel, Grisel Alejandra, op. cit., p. 216.

13 Sánchez Urrutia, Ana Victoria, op. cit., pp. 106-110.

14 Carpizo, Jorge, op. cit., p. 549.

15 Uribe Arzate, Enrique y Correa Esquivel, Grisel Alejandra, op. cit., p. 215. 
al ámbito constitucional mexicano, puesto que la Constitución ha sufrido varias mutaciones importantes a lo largo de su historia". ${ }^{16}$ La mutación es la flexibilidad real de nuestra Constitución, como le llama Carpizo. ${ }^{17}$ Sin embargo, por la experiencia histórica de México, debe observársele con un altísimo cuidado para que no refuerce la impunidad presidencial, sobre todo ante la carencia de herramientas para procesar la responsabilidad política del Ejecutivo.

La mutación constitucional como manifestación de las modificaciones no formales subyace, íntegra o en modalidad, bajo otras denominaciones, es lo que en Francia se ha nombrado costumbre constitucional o lo que en Italia se refiere como modificaciones constitucionales tácitas; podría ser también lo que Lucciola Trajtman Robles ${ }^{18}$ denomina "Constitución implícita", entendida no como la Constitución histórica sino el texto que rige en la realidad y que se aplica efectivamente, al margen de su propia letra. Constitución que, a su parecer, se funda en los valores de la convivencia social, y por tanto se transforma con los cambios sociales.

En la sentencia del Tribunal Constitucional español que rechaza el recurso presentado en 2005 por el Partido Popular para impugnar la figura del matrimonio entre personas del mismo sexo, la mayoría de los magistrados consideraron al desechar, que no forzosamente debiera mediar una reforma, que la Constitución "a través de una interpretación evolutiva se acomoda a las realidades de la vida moderna como medio para asegurar su propia relevancia y legitimidad". ${ }^{19}$

\section{EL PRINCIPIO DE LA NO INTERVENCIÓN}

La función de la no intervención es proteger, a través de la correcta interpretación de las normas de derecho internacional, el principio básico de la

16 Wong Meraz, Víctor Alejandro, Constitución mexicana. Reforma y mutación, México, Porrúa, 2010, p. 139. En la presencia de la mutación dentro de la práctica constitucional mexicana coinciden también, entre otros, Carpizo, Jorge, op. cit., pp. 596 y ss.; Uribe Arzate, Enrique y Correa Esquivel, Grisel Alejandra, op. cit., pp. 200, 201 y 207.

17 Carpizo, Jorge, op. cit., p. 583.

18 Trajtman Robles, Lucciola, "Derecho vivo y mutación constitucional", Revista Jurídica Docentia et Investigatio, Lima, Facultad de Derecho y Ciencia Política de la Universidad Nacional Mayor de San Marcos, vol. 9, núm. 1, 2007, p. 111.

19 Aceprensa, "Interpretación evolutiva" frente a mutación constitucional, Madrid, Fundación Casatejada, 16 de noviembre de 2012, disponible en https://www.aceprensa. com/articles/interpretacion-evolutiva-frente-mutacion-constitucional/. 
soberanía de un Estado, supuesto fundamental de la comunidad universal. Se trata de un mecanismo doctrinal, para precisar los límites externos de la influencia permisible que un Estado puede ejercer sobre otro en el orden internacional y para atenuar la desigualdad de poder entre las naciones. ${ }^{20}$

El principio de no intervención es una cuestión muy antigua que si bien algunos académicos consideran se gestó desde la misma aparición del Estado moderno, en el plano internacional su codificación comienza con la Convención sobre Derechos y Deberes de los Estados, más conocida como Convención de Montevideo, suscrita el 26 de diciembre de 1933, en cuyo artículo 8o. se estableció que "Ningún Estado tiene derecho de intervenir en los asuntos internos ni en los externos de otro". ${ }^{21}$ Esta disposición se complementó con el denominado Protocolo de Buenos Aires del 23 de diciembre de 1936 en el que se estableció que las altas partes contratantes declaran inadmisible la intervención de cualquiera de ellas, directa o indirectamente, y sea cual fuere el motivo, en los asuntos interiores o exteriores de cualquiera otra de las partes y que la violación de las estipulaciones de este artículo daría lugar a una consulta mutua, a fin de cambiar ideas y buscar procedimientos de avenimiento pacífico.

Al crearse la Organización de las Naciones Unidas, la Carta de San Francisco estableció en el artículo 2.7 que ninguna disposición de la Carta autorizará a las Naciones Unidas a intervenir en los asuntos que son esencialmente de la jurisdicción interna de los Estados. Posteriormente, la Asamblea General adoptaría diversas resoluciones sobre los principios de derecho internacional referentes a las relaciones de amistad y cooperación entre los Estados, incluyéndose, desde luego, la cuestión de la no intervención: la Resolución 1815 (XVII) del 18 de diciembre de 1962 que reitera lo enunciado en la Carta y la Resolución 2131 (XX) del 21 de diciembre de 1965 que es más explícita y monotemática en cuestión de la revisión de los principios, llevando por nombre "Declaración sobre la inadmisibilidad de la intervención en los asuntos internos de los Estados y protección de su independencia y soberanía", resaltando que

20 Sepúlveda, César, "La no intervención como norma legal internacional. Sus alcances", en Rabasa, Emilio O. (coord.), Los siete principios fundamentales de la política exterior de México, México, Partido Revolucionario Institucional, 1993, p. 19.

21 Sierra, Manuel J., Derecho internacional público, México, Porrúa, 1963, p. 162. 


\begin{abstract}
Ningún Estado tiene derecho de intervenir directa o indirectamente, y sea cual fuere el motivo, en los asuntos internos o externos de cualquier otro. Por lo tanto, no solamente la intervención armada, sino también cualesquiera otras formas de injerencia o de amenaza atentatoria de la personalidad del Estado, o de los elementos políticos, económicos y culturales que lo constituyen, están condenadas. ${ }^{22}$
\end{abstract}

El culmen del tratamiento en el seno de la Asamblea General de Naciones Unidas lo constituye, sin duda, la Resolución 2625 (XXV) del 24 de octubre de 1970, adoptada con motivo y el día del vigésimo quinto aniversario de la Organización. En dicha Resolución denominada "Declaración sobre los principios de derecho internacional referente a las relaciones de amistad y a la cooperación entre los Estados de conformidad con la Carta de las Naciones Unidas", se reitera lo dispuesto en las resoluciones precedentes con el agregado de que su incumplimiento constituiría una violación al derecho internacional.

Entonces, esa práctica recurrente de México se vio codificada nuevamente en la Carta de las Naciones Unidas de 1945 y en la Carta de la Organización de Estados Americanos de 1948, donde se encuentra, a decir de Bernardo Sepúlveda Amor "probablemente la formulación más acabada del principio de no intervención" desprendida de la redacción de su artículo 15 que señala que "Ningún Estado o grupo de Estados tiene derecho de intervenir, directa o indirectamente, y sea cual fuere el motivo, en los asuntos internos o externos de cualquier otro". ${ }^{23}$

Existen disposiciones en las resoluciones de la Corte Internacional de Justicia sobre la cuestión de la no intervención, en el caso Canal de Corfú de 1949, señalando que la no intervención es la manifestación de una política de fuerza que no tiene cabida en el derecho internacional, y en el caso de Las Actividades Militares y Paramilitares en y en contra de Nicaragua de 1986, donde reitera la existencia y vigencia del principio de no intervención y de que la normatividad internacional prohíbe inmiscuirse en asuntos internos de los Estados. Ambos fallos fueron expedidos en el contexto de la ya comentada Guerra Fría.

22 Asamblea General de las Naciones Unidas, A/RES/20/2131, 21 de diciembre de 1965, disponible en http://www.un.org/es/comun/docs/?symbol=A/RES/2131(XX).

23 Sepúlveda Amor, Bernardo, "Política exterior y orden constitucional: los fundamentos de una política de Estado”, en Rabasa, Emilio O., Los siete principios básicos de la política exterior de México, México, UNAM, 2005, p. 40. 
El fin de la Guerra Fría definitivamente cambió los criterios interpretativos del principio de no intervención, que no es más defensivo sino, como se concibió originalmente y no como se adaptó al conflicto bipolar, es decir, de alto respeto a la soberanía. Cierto es que el cambio de paradigma a la caída del Muro de Berlín provocó escepticismo y temores:

En los últimos años ha surgido una amplia corriente de opinión que pretende revisar el principio de no intervención y legitimar un supuesto derecho de injerencia en nombre de la protección de los derechos humanos y la promoción de las formas democráticas de gobierno. En su versión más radical, esta opinión sostiene que el concepto de soberanía ha quedado superado por los cambios en el sistema político internacional, la globalización de la actividad económica y los avances en materia de comunicaciones y transportes. ${ }^{24}$

El mismo Sepúlveda Amor señalaba que "La vigencia de un aspecto fundamental de la soberanía, el principio de la no intervención, en los asuntos internos de los Estados, posee una indudable solidez. El valor jurídico y político de ese principio descansa en un hecho: la soberanía continúa siendo el principio ordenador de las relaciones internacionales, y los lamentos por su declinación son evidentemente prematuros". ${ }^{25}$ Sin embargo, es evidente que ni la historia se terminó ni la soberanía de los países se debilitó. Cierto es que la acepción de la no intervención sí experimentó una modificación con el fin de la conflagración ideológica bipolar y la emergencia del llamado nuevo orden internacional.

Aún antes de que la concepción del principio fuera considerado desde otra óptica en las relaciones internacionales, se estimaba que está universalmente condenado en la teoría internacional, se proscriben y se consideran ilegales todas sus facetas: armada, política, económica, etcétera, porque evidentemente se trata de un acto de fuerza de un Estado poderoso contra un país débil. Sin embargo, esta rotundez quedaba atenuada en la medida que se señalaba que sólo quedaría permitida en unos cuantos casos excepcionales cuando mereciera el asentimiento y la participación de una mayoría de naciones, y cuando existieran además instrumentos jurídicos precisos

24 Sepúlveda Amor, Bernardo, "No intervención y derecho de injerencia: el imperio o decadencia de la soberanía”, en Seara Vázquez, Modesto (comp.), Las Naciones Unidas a los cincuenta años, México, FCE, 1995, p. 178.

25 Ibidem, p. 197. 
que la admitieran, ya que de otra manera, cualquier justificación no pasaría de ser un argumento retórico: ${ }^{26}$

la no intervención no siempre se justifica cuando representa un conflicto con valores universales más elevados asociados a los principios de funcionamiento de un sistema democrático y de defensa a los derechos humanos. Este postulado ejemplifica cuál debe ser el enfoque de la no intervención en el mundo contemporáneo, donde los abusos a los derechos humanos, la pobreza extrema, la inestabilidad de los gobiernos, el descontento social, entre otros males otrora considerados del dominio exclusivo del Estado, pueden trascender las fronteras nacionales con mayor facilidad y, por ende, afectar al resto de la comunidad internacional. ${ }^{27}$

En América, donde como en ningún otro lugar se tuteló el principio de no intervención, se han producido notables avances hacia el abandono del principio de no intervención respecto de circunstancias que quiebren o pongan en peligro la forma de gobierno democrática en un Estado de la región. ${ }^{28}$ Esto queda abiertamente manifiesto con el llamado Compromiso de Santiago de 1991 y la Carta Democrática Interamericana de 2001. En ambos documentos se invocan los principios de libre determinación y de no intervención, pero, sin considerarlos en conflicto. Los países integrantes del sistema Interamericano manifestaron y consintieron su compromiso con la defensa y promoción de la democracia representativa y de los derechos humanos en la región de forma indeclinable.

Con todo, el principio de no intervención con un alcance más limitado perdura y tiene - en nuestra opinión — dos ejes fundamentales: (i) la prohibición de ejercer coacción a un Estado para que adopte medidas económicas, políticas o de cualquier otra índole - que no impliquen el uso de la fuerza- - encaminadas a que subordine el ejercicio de sus derechos soberanos y obtener

26 Sepúlveda, César, op. cit., p. 19.

27 Cuesta Colunga, Antonio de la, "El principio de no intervención en la negativa de México a participar en operaciones de mantenimiento de la paz de Naciones Unidas: una justificación anacrónica”, Documento de Trabajo 209, México, Fundación Rafael Hernández Preciado, octubre de 2005, p. 41.

28 Tempesta, Guillermo, "Nuevas avenidas al principio de no intervención: la injerencia humanitaria y la intervención democrática", Revista de Relaciones Internacionales, La Plata, Universidad Nacional de La Plata, vol. 8, núm. 16, 1999, disponible en http:// revistas.unlp.edu.ar/RRII-IRI/article/view/1756/1646. 
de él ventajas de cualquier orden; y (ii) la intervención sistémica, esto es, la dirigida a cambiar el sistema político, económico y/o cultural que constituyen un Estado. ${ }^{29}$

\section{LA NO INTERVENCIÓN EN LA PRÁCTICA DIPLOMÁTICA MEXICANA Y SU INSERCIÓN EN LA CONSTITUCIÓN}

Ya se ha mencionado que la presencia y el arraigo de la no intervención en México obedecieron a que su historia registra un amplio catálogo de injerencias de potencias externas que tuvieron, ente otras consecuencias, la pérdida de más de la mitad del territorio y el riesgo de la viabilidad del sistema republicano.

Se ha señalado que en el contexto de la Revolución mexicana se "abre una nueva etapa del proyecto nacional, en la que la política exterior adquiere cimientos aún más sólidos. Con la Revolución, los principios de nuestra política exterior son incorporados a los objetivos de los gobiernos emanados de aquélla". ${ }^{30}$ No es fortuito, además de incentivar el sentimiento nacionalista, en el contexto de la Revolución se dan infaustos acontecimientos intervencionistas, como el Pacto de la Embajada para derrocar al presidente Madero; la invasión al puerto de Veracruz en 1914 y la llamada expedición punitiva del general Pershing que, bajo el pretexto de capturar a Francisco Villa, implicó la internación del ejército norteamericano al territorio nacional, esto último cuando ya Venustiano Carranza ocupaba la presidencia.

Es precisamente Carranza, quien en su Informe al Congreso presentado el 1o. de septiembre de 1918, enunció los principios que regirían la postura de México con respecto a sus relaciones internacionales, es decir, lo que ahora se conoce con el nombre de "Doctrina Carranza". En dicho informe señaló que "Las ideas directrices de la política internacional son pocas, claras y sencillas. Se reducen a proclamar: Que todos los países son iguales; deben respetar mutua y escrupulosamente sus instituciones, sus leyes y soberanía; que ningún país debe intervenir en ninguna forma y por ningún motivo en los asuntos interiores de otro". ${ }^{31}$ Estableció sin ambages que todos

29 Idem.

30 Senado de la República, Diario de los Debates, México, 9 de noviembre de 1987, p. 6 .

31 Idem. 
los países deberían someterse estrictamente y sin excepciones, al principio universal de no intervención. En su concepción, Carranza argumentaba que a partir de este conjunto de principios se modificaba profundamente el concepto de la diplomacia utilizado en esos días, enfatizando que ésta no debía servir para la protección de intereses de particulares, ni para poner al servicio de éstos la fuerza y la majestad de las naciones, y que tampoco debía servir para ejercer presión sobre los gobiernos de los países débiles. Muy probablemente la concepción de lo que hoy denominamos Doctrina Carranza se debió al pensamiento de don Isidro Fabela quien era consejero del mandatario y, como bien se sabe, estudioso y experto de las cuestiones internacionales.

El 27 de septiembre de 1930, el subsecretario, encargado de despacho de la Secretaría de Relaciones Exteriores, Genaro Estrada, envía una circular a las representaciones diplomáticas mexicanas con las instrucciones sobre la posición que deberían asumir "con motivo de cambios de régimen ocurridos en algunos países de América del Sur" (golpes de Estado). ${ }^{32}$ De dicho documento se desprendería lo que se conoció, en principio, como "Doctrina México" y que algunos quisieron llamar "Doctrina Ortiz Rubio", por ser el presidente en turno, pero que se consolidaría con el apellido de su redactor. La doctrina establece que

México no se pronuncia en el sentido de otorgar reconocimientos porque considera que ésta es una práctica denigrante [...] el gobierno de México se limita a mantener o retirar, cuando lo considere procedente, a sus agente diplomáticos [...] sin calificar, ni precipitadamente, ni a posteriori, el derecho que tengan las naciones extranjeras para aceptar, mantener o sustituir a sus gobiernos o autoridades. ${ }^{33}$

La Doctrina Estrada es una modalidad del principio de no intervención en la faceta del reconocimiento de gobiernos, que viene a reforzar la Doctrina Carranza de la no intervención, y sirve como paradigma de la práctica

32 Estrada, Genaro, Obras completas, México, Siglo Veintiuno Editores, 1988, t. II, pp. 144 y 145. El acontecimiento que da origen al pronunciamiento de Estrada es el primer golpe militar en la historia de Argentina, del 6 de septiembre de 1930, por el cual fue destituido el presidente Hipólito Yrigoyen, pero con los antecedentes de los golpes en Bolivia y en Perú en mayo y agosto, respectivamente, de ese mismo año.

33 Idem. Cursivas en el original. 
diplomática mexicana que vendría a consolidarse como herramienta toral de la política exterior mexicana durante el periodo de la Guerra Fría.

Si bien, las directrices de la política exterior mexicana se debieron a los principios sustentados en las doctrinas generadas en el quehacer diplomático nacional, así como en los instrumentos jurídicos internacionales que los enunciaban, y los cuales México había suscrito, surgió la interrogante de si éstos debieran estar plasmados en el texto constitucional. Emilio O. Rabasa, refiere:

Cuando fui secretario de Relaciones Exteriores (1970-1975) tanto por iniciativa propia como por sugerencia de especialistas competentes, estudié, en diversas ocasiones, la posibilidad de incorporar a la Constitución los principios básicos de la política exterior mexicana. Si no llegué a proponer al presidente Echeverría tan atractiva adición constitucional fue - esencialmente- por las dos siguientes razones: 1. En los términos del artículo 133 vigente, todos los tratados son parte de la "Ley Suprema de la Unión" [...] ¿por qué, entonces, insertar en la Constitución lo que ya formaba parte de la misma, a través de los tratados? 2. [...] la nueva norma podría no contener todos los principios fundamentales y perennes de México en esta materia. Más aún quizá sería el medio para que cada presidente asentara sus preferencias de momento en esa materia. ${ }^{34}$

Fue hasta la administración del presidente Miguel de la Madrid que se decidió enviar la iniciativa respectiva para incorporar los principios de política exterior a la Constitución. La iniciativa en cuestión está publicada en el Diario de los Debates del Senado de la República del 9 de noviembre de 1987, irónicamente dos años exactos antes de la caída del Muro de Berlín que, alegóricamente, representa el fin de la Guerra Fría y el advenimiento de la nueva concepción del principio de no intervención dentro del orden internacional.

El presidente De la Madrid en su exposición de motivos señala que la política exterior de México entiende que ante los problemas de una nación, ningún interés extranjero está legitimado para imponer su voluntad; argumenta que la conducta internacional del país ha mantenido apego estricto a los principios propuestos, lo que se habría traducido en una posición de negociación sólida y una voz respetada. Considera que la legitimidad de di-

34 Rabasa, Emilio O. (coord.), Los siete principios fundamentales..., cit., pp. 12 y 13. Cursivas en el original. 
chos principios le garantiza a México una mayor efectividad en la defensa de sus intereses y que México ha mostrado siempre su decisión de solidarizarse con los pueblos que luchan por su libertad y de condenar todo acto intervencionista. Fundamenta además que:

Por el papel que México desempeña en el contexto internacional y la manera firme y perseverante con la que el país ha venido sustentando los principios esenciales de la política exterior, resulta importante que éstos figuren en el texto de la ley fundamental. Ciertamente, dichos principios son coincidentes con el espíritu del constituyente; empero, la trascendencia que tiene la política exterior para el Estado mexicano exige que la incorporación sea explícita. ${ }^{35}$

La iniciativa presidencial no tuvo ningún contratiempo a lo largo del proceso de reforma constitucional, porque el sistema político imperante en esas fechas, con un alto nivel de influencia presidencial, no se prefiguraba como obstáculo, y también porque la nobleza del contenido no se prestaba necesariamente al disenso. Fue así que se aprobó tersamente, sin aspavientos. En su análisis y debate:

La comisión dictaminadora estima que la iniciativa de reforma constitucional propuesta, reviste una importancia fundamental para el Estado de México [sic]. Su contenido se refiere a principios estructurales que servirán para la buena marcha de la nación, es de la mayor relevancia dentro del proceso político transformador no sólo hacia el exterior sino también en lo interno. Existe una vinculación innegable entre los principios políticos que el Estado Mexicano sustenta en los asuntos internos y en los internacionales. ${ }^{36}$

La reforma se publicó en el Diario Oficial de la Federación del 11 de mayo de 1988. Los principios se insertaron en las facultades del Ejecutivo, artículo 89, específicamente en la fracción X que le concedía desde la redacción original la potestad de dirigir las negociaciones diplomáticas y celebrar tratados con las potencias extranjeras. Lo anterior fue reformado en los siguientes términos:

X. Dirigir la política exterior y celebrar tratados internacionales, sometiéndolos a la aprobación del Senado. En la conducción de tal política, el

Senado de la República, op. cit., pp. 7-9.

36 Cámara de Diputados, Diario de los Debates, México, núm. 47, 23 de diciembre de 1987. 
titular del Poder Ejecutivo observará los siguientes principios normativos: la autodeterminación de los pueblos; la no intervención; la solución pacífica de controversias; la proscripción de la amenaza o el uso de la fuerza en las relaciones internacionales; la igualdad jurídica de los Estados; la cooperación internacional para el desarrollo; y la lucha por la paz y la seguridad internacionales. ${ }^{37}$

Es innegable que, en algunas ocasiones, México no se haya constreñido al principio de no intervención y éste haya sido vulnerado, "pues incluso en el mero plano teórico es casi impensable una interacción política internacional sin generar algún tipo de rozamiento con el ámbito reservado a otros Estados". ${ }^{38}$

\section{Excepciones a la aplicación del principio de no intervención}

\section{A. Guerra civil española}

Cuando se refiere el apoyo de México a los republicanos españoles, se relaciona directamente a la gran cantidad de refugiados que fueron recibidos en México, particularmente, los intelectuales y los llamados "Niños de Morelia", pero el apoyo no se limitó a eso: "Sin duda, el gesto más arriesgado y comprometido del gobierno de Cárdenas en ayuda de la República española fue suministrarle armas... Desde el principio, el gobierno mexicano puso a disposición de la República la producción total de su Fábrica Nacional de Armamentos". ${ }^{39}$

\section{B. Revolución sandinista}

Si bien México intentó sostener al máximo su postura no intervencionista, tras la fallida insurrección sandinista de septiembre de 1978 no pudo ocul-

37 Decreto por el que se reforma la fracción X del artículo 89 de la Constitución Política de los Estados Unidos Mexicanos, Diario Oficial de la Federación, México, 11 de mayo de 1988 , p. 3. Con la reforma integral en materia de derechos humanos $(D O F, 10$ de junio de 2011), se adicionó un nuevo principio: el respeto, la protección y la promoción de los derechos humanos.

38 Gutiérrez Baylón, Juan de Dios, "La no intervención”, en Rabasa, Emilio O., Los siete principios básicos..., cit., p. 79.

39 Ojeda Revah, Mario, México y la Guerra Civil Española, Madrid, Turner Publicaciones, 2005, p. 139. 
tar más su simpatía por la facción rebelde. ${ }^{40}$ Desde luego que el presidente nicaragüense Anastasio Somoza, protestaría por la actitud intervencionista de México en los asuntos de Nicaragua.

El 20 de mayo de 1979, el presidente José López Portillo anunció el rompimiento de relaciones diplomáticas con Nicaragua "porque nuestro país no puede soportar que la permanencia de ningún régimen político entrañe, para el pueblo que lo vive y que lo sufre, no sólo la servidumbre, sino el abuso inaceptable". ${ }^{41}$ Invitó a los países latinoamericanos a seguir el ejemplo y romper con el gobierno de Somoza, además de señalar que en Nicaragua se estaba cometiendo un genocidio. El canciller del gobierno somocista reaccionó señalando que la decisión de México era "insólita y precipitada", declarando además "me sorprende la actitud del gobierno mexicano porque abandona su tradicional Doctrina Estrada de no intervención, pero cada gobierno es libre de ejercer su propia soberanía". ${ }^{42}$

En los meses inmediatos a julio de 1979, el respaldo político mexicano se entendía como la promesa de defender como propia la causa de Nicaragua. López Portillo visitó Nicaragua en tres ocasiones, en tanto que la llegada de comandantes sandinistas a México se hizo más frecuente. Se estima que entre 1979 y 1981 el apoyo material y económico a la revolución sandinista llegó a superar los 500 millones de dólares.

López Portillo declararía que "ignorar los principios básicos de la política internacional de México, que no se ha desviado ni en la época más obscura de la dictadura, y no romper relaciones diplomáticas con Nicaragua en los términos de la Doctrina Estrada hubiera sido una inconsecuencia histórica" ${ }^{43}$ No se entiende qué habrá querido decir, pero lo cierto es que "con el apoyo a la insurgencia nicaragüense se había hecho a un lado el principio de no-intervención". ${ }^{4}$

40 Herrera León, Fabián, "El apoyo de México al triunfo de la revolución sandinista: su interés y uso políticos", Anuario Colombiano de Historia Social y de la Cultura, Bogotá, Universidad Nacional de Colombia, vol. 38, núm. 1, enero-junio de 2011, p. 228.

41 "México rompe sus relaciones con Nicaragua", El Informador, Guadalajara, 21 de mayo de 1979, p. 1.

42 "Comentan el rompimiento de México con Nicaragua", El Informador, Guadalajara, 22 de mayo de 1979, p. 1.

43 "Inconsecuencia histórica no romper con Nicaragua", El Informador, Guadalajara, 25 de mayo de 1979, p. 1.

44 Herrera León, Fabián, op. cit., p. 230. 


\section{Comunicado franco mexicano}

E1 28 de agosto de 1981, los presidentes de México y Francia, José López Portillo y François Miterrand respectivamente, por medio de sus ministros de Relaciones Exteriores, Jorge Castañeda y Álvarez de la Rosa y Claude Cheysson, formularon una declaración conjunta sobre el conflicto de El Salvador que presentaron al presidente del Consejo de Seguridad de la Organización de la Naciones Unidas, Jorge Illueca. Dicha declaración, hoy conocida como el comunicado franco-mexicano, reconocía a la alianza del Frente Farabundo Martí de Liberación Nacional con el Frente Democrático Revolucionario como "fuerza política representativa" que debía participar en la solución política negociada del conflicto sin injerencia extranjera.

El hecho sorprendió al mundo entero. Si bien, los fines eran loables, pues proponía abrir una nueva vía de solución política y pacífica frente al estancamiento de las negociaciones en medio de una dolorosa guerra civil de elevadísimo costo humano y político; no había duda, se trataba de un acto abiertamente intervencionista. El gobierno salvadoreño del presidente Napoleón Duarte acusó de "injerencia" a la "Declaración Franco Mexicana". El canciller mexicano Jorge Castañeda declararía "No lo veo por el lado de una clara intervención, ni de una negación a la política exterior". ${ }^{45}$ Días después, el 2 de septiembre, se conocería en respuesta la "Declaración de Caracas", por la cual los gobiernos de Argentina, Bolivia, Chile, Colombia, República Dominicana, Guatemala, Honduras, Paraguay y Venezuela manifestaban la inquietud ante la toma de posición de los gobiernos francés y mexicano a favor de "uno de esos movimientos subversivos, que por la violencia intentan cambiar el porvenir democrático, y la libre determinación del pueblo salvadoreño". ${ }^{46}$

Los ejemplos enunciados son prueba de que en la fase más "dura” de la aplicación del principio de no intervención, México ejerció excepciones, porque así convenía a los intereses de su práctica diplomática en el momento referido. Existen otros ejemplos: la ruptura de relaciones diplomáticas con Chile en 1973, tras el golpe militar de Pinochet, o la solicitud enviada al secretario de la ONU para que se condene al franquismo y se expulse a

45 "México no es intervencionista: Jorge Castañeda", El Informador, Guadalajara, 2 de septiembre de 1981, p. 1.

46 "Preocupa a 9 países el pronunciamiento franco-mexicano", El Informador, Guadalajara, 3 de septiembre de 1981, pp. 1 y 3. 
España de la ONU o en la Asamblea General de la ONU, el voto de México a favor de una declaración señalando que el sionismo era una forma de racismo.

\section{LOS NUEVOS CRITERIOS INTERPRETATIVOS DEL PRINCIPIO CONSTITUCIONAL EN EL CASO MEXICANO}

Si bien, en su momento, mucho se celebró la incorporación de los principios, señalándose incluso que su violación o incumplimiento implicaría, respectivamente, infringir la Ley Suprema o no acatarla, y que ambas actitudes negativas podrán ser señaladas y reclamadas por todos los mexicanos, ${ }^{47}$ en el caso particular del cambio en el criterio interpretativo del principio de no intervención, trajo consigo el aminoramiento del entusiasmo, la duda en cuanto a la pertinencia de su inserción al texto constitucional, e incluso el reniego por dicha causa.

El agotamiento de la Doctrina Estrada se dio de forma paralela a la flexibilización del principio de no intervención, pues se ha aseverado que "la relación de la forma del gobierno y el derecho internacional es aplicable durante la vigencia del modelo de la Carta por lo menos hasta la caída del muro de Berlín". ${ }^{48}$ Por causas externas e internas, la actuación de la diplomacia mexicana también comenzó a sentir la presión del cambio de criterio en la comprensión del principio de no intervención. México se vio compelido a cambiar sus posturas en materia de derechos humanos y democracia. Enseguida se enlistan instrumentos situaciones o posturas que demuestran que la práctica política en materia de relaciones internacionales ha experimentado un viraje que manifiesta que el principio de no intervención no es asumido como lo fue desde que se acuñó la Doctrina Carranza, pero sobre todo respecto del actuar en el contexto de la Guerra Fría.

\section{La carta democrática de la Organización de los Estados Americanos}

El 11 de septiembre de 2001, reviste una efeméride muy importante para el sistema hemisférico interamericano, pues dicho día se suscribió en Lima

\footnotetext{
47 Rabasa, Emilio O. (coord.), Los siete principios fundamentales..., cit., p. 14.

48 Tempesta, Guillermo, op. cit.
} 
el documento denominado Carta Democrática Interamericana, llamada a promover la democracia en el continente y a tomar medidas colectivas ante la ruptura de ésta en alguno de los países parte.

Su adopción tenía como antecedentes el Compromiso de Santiago y el artículo segundo de la Resolución 17 del Comité Jurídico Interamericano del 19 de agosto de 2000, en el cual se asentaba que "el principio de no intervención y el derecho de cada Estado del Sistema Interamericano a elegir, sin injerencia externa, su sistema político, económico y social y a organizarse en la forma que más le convenga, no pueden amparar la violación de la obligación de ejercer efectivamente la democracia representativa en dicho sistema y organización". ${ }^{49}$

Ya desde el primer considerando se señala que "la Carta de la Organización de los Estados Americanos reconoce que la democracia representativa es indispensable para la estabilidad, la paz y el desarrollo de la región, y que uno de los propósitos de la OEA es promover y consolidar la democracia representativa dentro del respeto del principio de no intervención". ${ }^{50} \mathrm{Du}$ rante los debates de redacción, siempre estuvo presente el principio de no intervención como sombra de las medidas propuestas y la forma en cómo salvar el escollo sin violentar los textos asumidos en el contexto de la Guerra Fría. Elisa Ruiz, representante del Paraguay, estableció que

Esta Carta resuelve acertadamente la falsa dicotomía entre diferentes principios consagrados en la Carta de la OEA, como los de la defensa de la democracia y los de no intervención. No se trata de contraponer un principio al otro, buscando en vano la mutua neutralización y consecuente parálisis, esquema que en otros tiempos tuvo no pocos exégetas y un buen número de discípulos que preferían la indiferencia no intervencionista a la solidaridad democrática. ${ }^{51}$

En el mismo sentido se pronunció Didier Opertti, ministro de Relaciones Exteriores de Uruguay, al señalar que "fue necesario que se proclamaran valores que estuvieren por encima de los principios operativos del sistema, para que la comunidad regional entera asumiera que el principio de no inter-

49 Resolución 17 del Comité Jurídico Interamericano del 19 de agosto de 2000, en Organización de Estados Americanos, Carta Democrática Interamericana. Documentos e Interpretaciones, Washington, 2003, p. 281.

50 Organización de Estados Americanos, Ibídem, p. 3.

51 Ibidem, p. 73. 
vención no puede constituirse en el único principio definidor del sistema". ${ }^{52}$ Por su parte, Jorge G. Castañeda, entonces secretario de Relaciones Exteriores, intervino para señalar que México consideraba que la adopción de la Carta Democrática Interamericana representaba un avance fundamental en la articulación de la nueva arquitectura internacional, ya que esto había favorecido en el pasado a la aceptación tácita de la comunidad internacional de regímenes autoritarios y dictatoriales, y que esa tolerancia tendía ya a desvanecerse, y que debía desaparecer por completo; para Castañeda "la Carta Democrática Interamericana constituye una profesión de fe, un compromiso adoptado de manera soberana por las naciones de América [...] Se trata de un proceso por el cual la política exterior de nuestras naciones asume una nueva convicción humanista". ${ }^{53}$

La Carta Democrática establece que la ruptura del orden democrático o una alteración del orden constitucional que afecte gravemente el orden democrático en un Estado miembro constituye, mientras persista, un obstáculo insuperable para la participación de su gobierno en órganos del Sistema Interamericano, aún más, cualquier Estado miembro o el secretario general podrá solicitar la convocatoria inmediata del Consejo Permanente para realizar una apreciación colectiva de la situación y adoptar las decisiones que estime conveniente. Se puede convocar a la Asamblea General del Organismo que podría tomará la decisión de suspender a dicho Estado miembro del ejercicio de su derecho de participación en la OEA con el voto afirmativo de los dos tercios de los Estados miembros. Esto último ya se ha aplicado en los casos de Honduras y Paraguay. México no se ha podido sustraer de cumplir las obligaciones que asigna la mencionada Carta. Incluso en el caso de Honduras, presidía al Grupo de Río y tuvo que convocar a una reunión extraordinaria en la cual se condenó el golpe.

\section{El examen periódico universal}

Durante mucho tiempo, específicamente durante los gobiernos emanados del Partido Revolucionario Institucional en el contexto de la Guerra Fría, México mantuvo una posición de extrema cautela al momento de pronunciarse sobre la observancia de los derechos humanos en otros países, por

\footnotetext{
52 Ibidem, p. 231.

53 Ibidem, p. 309.
} 
varias razones, quizá la más importante, porque ello daría pie a que de igual manera México fuera escrutado en la materia, y los resultados, señala la historia, no serían óptimos para el gobierno en turno.

Un ejemplo muy ilustrativo de esta forma de actuar pudiera ser la Masacre de la Plaza de Tiananmen de Pekín, en junio de 1989: el Gobierno, a través de la cancillería, tardó dos días en emitir un comunicado en el que señalaba que "El Gobierno mexicano ha estado siguiendo de cerca los acontecimientos de los últimos días en la República Popular China, especialmente para cerciorarse de la integridad física y la seguridad de nuestros connacionales que actualmente residen o se encuentran en ese país. Como en todo caso de enfrentamiento que lleve a la pérdida de vidas humanas"; 54 para terminar expresando México lamentaba profundamente los decesos que se habían presentado en Beijing, y que la Secretaría de Relaciones Exteriores confiaba en que pudieran dirimirse las diferencias de manera pacífica, por lo que continuaba en constante enlace con la Embajada de México para estar debidamente informada de los acontecimientos. No hay condenas, no se mencionan los derechos humanos.

Cuando el tema de los derechos humanos se incorporó de lleno en la entonces llamada "nueva agenda internacional", México empezó a dar señales de cambio, el cual se empieza a gestar de manera más importante durante el gobierno de Ernesto Zedillo Ponce de León (1994-2000), tomándose la decisión de invitar a organizaciones internacionales para observar la situación de los derechos humanos en el país, destacando las visitas de la Comisión Interamericana de Derechos Humanos y de la alta comisionada de Naciones Unidas para los Derechos Humanos. Sin embargo, de mayor trascendencia fue la medida de dicho gobierno para reconocer la jurisdicción de la Corte Interamericana de Derechos Humanos. También en la administración zedillista se comenzaron a asumir ciertas actitudes o manifestaciones críticas respecto de la situación de derechos humanos, como en el caso de Cuba cuando por primera vez México se abstiene de apoyarle en las votaciones en la Comisión de Derechos Humanos de Naciones Unidas, y la entonces canciller, Rosario Green, se reúne con la disidencia en La Habana. El cambio en materia de derechos humanos se va a consolidar durante los gobiernos de la llamada "alternancia", de hecho, Jorge G. Castañeda afirmó que en "la nueva política exterior que el presidente Vicente Fox ha trazado para

54 "México lamenta los acontecimientos en Beijing: SRE", El Informador, Guadalajara, 7 de junio de 1989, pp. 1 y 3. 
nuestro país, el impulso a la democracia y los derechos humanos constituye un eje rector de la actividad internacional de nuestra nación". ${ }^{55}$

Coincidiendo en fechas, surge en el ámbito de las Naciones Unidas, el Consejo de Derechos Humanos como sustituto de la Comisión de Derechos Humanos creada en los albores de la organización y con marcado reflejo de las políticas de un mundo bipolar que comenzaba a gestarse. El Consejo comenzó sus funciones en junio de 2006 y México decidió ser un protagonista en el mismo. Obtuvo uno de los 47 asientos, pero lo más importante, le correspondió asumir la primera presidencia del Consejo en la persona del embajador Alfonso de Alba. En la tendencia de querer ser un protagonista en el Consejo, México buscó y obtuvo la reelección para el periodo trienal 2009-2012, y de acuerdo a la normatividad del Consejo, quedaba impedido para reelegirse de nuevo de forma consecutiva hasta en tanto transcurriese un año mínimo de por medio, fue así que México presentó su candidatura y obtuvo el asiento para el periodo 2014-2016.

El nuevo Consejo trajo consigo el examen periódico universal (EPU) como mecanismo de escrutinio y evaluación de la observancia de derechos humanos en todos los países miembros de la ONU en un esquema que no le permite a México, que además aspira a ser un importante protagonista en la materia, permanecer pasivo o sigiloso y, por lo tanto, abstenerse de emitir opiniones, críticas o recomendaciones a otros Estados en materia del cumplimiento de derechos humanos. El EPU posee una fase de diálogo interactivo en el que participan los 47 Estados miembros del Consejo (pudiendo asistir otros Estados miembros de la ONU, así como actores interesados, como las organizaciones no gubernamentales y las instituciones nacionales de derechos humanos). Los integrantes del Consejo integran las troikas. ${ }^{56}$ La primera sesión del EPU se celebró el 7 de abril de 2008, y actualmente está en proceso de desahogo el segundo ciclo. A cada país le corresponde ser examinado cada cuatro años y medio. Durante los dos ciclos (abril 2008 a junio de 2015), México ha recibido 366 recomendaciones y ha formulado un total de 948 (lo que lo coloca como el quinto país que

55 Organización de Estados Americanos, op. cit., p. 309.

56 La troika consiste en tres delegados de Estados que apoyan al Grupo de Trabajo (compuesto por todos los miembros del Consejo); son seleccionados por sorteo entre los países miembros, Su tarea consiste en recibir las preguntas, así como las cuestiones presentadas de forma previa por los Estados, y las retransmite al Estado examinado. También se encarga de preparar el informe del Grupo de Trabajo. Uno de los miembros de la troika está encargado de presentar el informe antes de su adopción por el Grupo de Trabajo. 
más ha emitido recomendaciones a Estados examinados). Adicionalmente, ha integrado 20 troikas. $^{57}$

\section{El conflicto sirio}

Un caso particularmente interesante es el de Siria. México ha sido muy crítico en el tratamiento del tema al interior del Consejo de Derechos Humanos. El 22 de agosto de 2011, México respaldó la creación de una comisión de investigación independiente que indagara las atrocidades cometidas y que diera paso a la rendición de cuentas de los responsables. Posteriormente, el 19 de septiembre de 2011, hizo un llamado al gobierno sirio "a cumplir con su responsabilidad, terminar con las violaciones a los derechos humanos y sancionar a los responsables de su comisión". Añadiendo que el Consejo debería continuar asumiendo su responsabilidad y tomar decisiones contundentes, puntuales e impostergables.

Muy polémico y debatido, al interior de la cancillería, fue el discurso pronunciado el 13 de febrero de 2013, por la embajadora Yanerit Morgan Sotomayor, representante permanente alterna de México ante la Organización de las Naciones Unidas, durante el debate de la Asamblea General relativo al Informe del Consejo de Derechos Humanos sobre la situación en Siria, donde señaló:

Las Naciones Unidas no pueden permanecer pasivas e indiferentes frente a aquellas situaciones que amenazan en degenerar en nuevas tragedias humanitarias. El Consejo de Seguridad tiene la responsabilidad de actuar de manera oportuna y decisiva cuando se utiliza la violencia indiscriminada en contra de la población civil. El principio de no intervención encuentra su límite cuando están en juego valores esenciales de la comunidad internacional y se presentan violaciones graves a los derechos fundamentales de los pueblos y de los individuos, más aún cuando éstas han sido calificadas de crímenes contra la humanidad. ${ }^{58}$

57 Información disponible en http://www.upr-info.org/database/statistics/.

58 Intervención de la embajadora Yanerit Morgan Sotomayo durante el debate de la Asamblea General relativo al Informe del Consejo de Derechos Humanos sobre la situación en Siria, 13 de febrero de 2013, disponible en http://mision.sre.gob.mx/onu/images/ D12FEB13D01.pdf. 


\section{La crisis argentina de los llamados "fondos buitre"}

Tras la crisis económica de 2001, Argentina declaró la moratoria de su deuda externa. Años después comenzó a renegociar la deuda con sus acreedores, aceptando su ofrecimiento el $93 \%$ de los tenedores, pero dentro del restante $7 \%$ se encuentran los llamados "fondos buitre", entendidos como los especuladores que se dedican a comprar deuda soberana de países que están en situaciones financieras críticas, o empresas que están inmersas en problemas económicos, a un precio muy bajo, con la intención de venderlos a un precio considerablemente más elevado del que pagaron por ello. Dos de los tenedores de "fondos buitre" acudieron a la justicia norteamericana, y el caso llegó hasta la Corte Suprema de dicho país. En este contexto, varios países como Francia, Brasil y México apoyaron a Argentina con la figura de amicus curiae ${ }^{59}$ ante la Corte Suprema de los Estados Unidos. Considerando si debe sólo considerarse un acto solidario que no implica una desatención al principio de no intervención. Cuando el caso llegó a la Corte Suprema con el objeto de que ese alto tribunal norteamericano revisara dicha apelación es que, oficialmente, México decide intervenir en la cuestión. En este sentido, en marzo de 2014, México envió cartas a cada una de las partes para solicitar su "no objeción" de que México presentara un escrito de "Amigo de la Corte" en apoyo de la mencionada petición. Ambas partes expresaron su anuencia. De acuerdo con la Secretaría de Hacienda y Crédito Público, que no la de Relaciones Exteriores:

México considera que dichas órdenes (injunction remedies) podrían contravenir el régimen internacional de inmunidad jurisdiccional de los Estados y de sus bienes, pudiendo implicar condiciones menos favorables para acceder al financiamiento internacional, por lo que decidió apoyar la petición de apelación mencionada, con el propósito de que la Suprema Corte de Justicia de los Estados Unidos revise dicho aspecto. ${ }^{60}$

59 Amicus Curiae, expresión latina que puede traducirse como "amigo de la corte", es una institución derivada del derecho romano que se utiliza con mucha frecuencia en el derecho anglosajón. Consiste en posibilitar a terceros que no son parte de un litigio, pero que consideran poseer un interés en la resolución de éste, a presentar una opinión con la intención de aportar elementos que pudieran contribuir a los elementos de convicción del juzgador.

60 Comunicado 024/2014, Secretaría de Hacienda y Crédito Público, México, 25 de 
Asimismo, se menciona que la decisión de intervenir obedece a las posibles implicaciones que la aplicación de las órdenes dictadas por el juez de Distrito podrían tener para cualquier Estado soberano en los mercados internacionales de deuda; que México es un emisor recurrente en los mercados internacionales de deuda soberana y que se considera que las órdenes dictadas por el juez de Distrito podrían ir en contra de ciertos principios que rigen el derecho de inmunidad soberana. No está en duda la conveniencia y pertinencia de ejercer este recurso, sino que al hacerlo, aun con la mejor intención, se estaba faltando al principio de no intervención, entendido desde la óptica de la tradición de la política exterior mexicana. El 16 junio de 2014, la Corte Suprema de Estados Unidos rechazó aceptar la apelación. ${ }^{61}$

\section{Participación en las operaciones para el mantenimiento de la paz (OMP)}

Se ha afirmado que "tradicionalmente los principales opositores a la participación de tropas nacionales en OMP han sido los mismos miembros de las Fuerzas Armadas mexicanas. En los gobiernos anteriores al del presidente Fox, un amplio sector de las élites políticas y diplomáticas de México estaba de acuerdo con esta postura de los militares mexicanos", ${ }^{62}$ añadiendo que el principal argumento esgrimido por quienes se oponen al envío de efectivos militares a las OMP, es el respeto al principio de no intervención plasmado en el artículo 89, fracción X, de la Constitución. En la cancillería también había una corriente de opositores: "los simpatizantes con una política exterior principista manipulan el noble principio de la no intervención y con esto propician el aislamiento internacional de nuestro país, mientras por otro

marzo de 2014, disponible en http://www.shcp.gob.mx/Biblioteca_noticias_home/comu nicado_024_2014.pdf.

61 En este caso se han mostrado dos caras de la diplomacia mexicana, la que se describe suscrita por la SHCP y la de la cancillería: la Asamblea General de la ONU adoptó el 9 de septiembre de 2014 la resolución 68/304 promovida en el contexto de la crisis de los "fondos buitre", y en la que se pugna por el establecimiento de un marco jurídico multilateral para regular la reestructuración de la deuda pública de los países. Promovido por Bolivia en su calidad de presidente del G77 más China, el texto obtuvo 124 votos a favor, 11 en contra y 41 abstenciones. México es uno de los países que optaron por la abstención.

62 Cuesta Colunga, Antonio de la, op. cit., p. 4. 
lado manifiestan una supuesta vocación multilateralista". ${ }^{63}$ Un ejemplo es el comunicado de la cancillería, de 1999, que señalaba:

1. México nunca ha participado, ni participará, con tropas en operaciones de mantenimiento de la paz de Naciones Unidas. Esto es así por razones constitucionales. 2. El Gobierno de México ha manifestado en incontables ocasiones que la política exterior de la República se apega estrictamente a los principios constitucionales de solución pacífica de las controversias y de no intervención. ${ }^{64}$

Después de muchos debates, polémica, foros de consulta, declaraciones y desmentidos, renuncias de funcionarios, México decide anunciar su participación en este tipo de operaciones o de enviar "cascos azules" como se les conoce popularmente. Puede ser que los antecedentes ya descritos hayan sido aprovechados por la administración federal para tomar esta decisión.

Al participar en el debate de alto nivel en la Asamblea General de Naciones Unidas (26 de septiembre de 2014), el presidente Peña Nieto señaló que México estaba dispuesto a ser parte activa de la transformación de las Naciones Unidas, que se apoyaba y valoraban las operaciones para el mantenimiento de la paz como el instrumento de ayuda a los países a superar conflictos y crear condiciones para una paz duradera, mediante acciones de reconstrucción, asistencia humanitaria y seguridad; que "por eso, México ha tomado la decisión de participar en las operaciones de mantenimiento de la paz de las Naciones Unidas, realizando labores de índole humanitaria en beneficio de la población civil. Nuestra participación será atendiendo a un mandato claro del Consejo de Seguridad, y estará apegada a los principios normativos de política exterior establecidos en nuestra Constitución". ${ }^{65}$

Previo al discurso del presidente Peña Nieto en Naciones Unidas, la prensa comenzó a especular sobre este punto, a lo cual la diputada Amalia García Medina del Partido de la Revolución Democrática manifestó su preocupación

63 Ibidem, p. 47.

64 Secretaría de Relaciones Exteriores, Boletín 203/99 de 26 de mayo de 1999, citado en Gutiérrez Baylón, Juan de Dios, op. cit., pp. 82 y 83.

65 Intervención del presidente Enrique Peña Nieto, en el Segmento de Alto Nivel del Debate General de la Asamblea General de Naciones Unidas (26 de septiembre de 2014), disponible en http://www.presidencia.gob.mx/articulos-prensa/intervencion-del-presiden te-de-los-estados-unidos-mexicanos-licenciado-enrique-pena-nieto-en-el-segmento-dealto-nivel-del-debate-general-de-la-asamblea-general-de-naciones-unidas/. 
Tenemos que hacer una revisión de nuestra política exterior a partir de la tradición que se tiene de no intervención, de una tradición pacifista, una tradición que contribuye al diálogo y una tradición de un país abierto a ser el hogar donde aquellos que son perseguidos políticos o aquellos que por razones humanitarias requieren respaldo, encuentren una apertura. Y mi preocupación la expreso, porque estando de acuerdo con lo que hoy se pone a votación [reformas a la Ley de Refugiados y Protección Complementaria], me preocupa por otro lado que México pudiera participar con tropas, con miembros del Ejército, en los Cascos Azules en otros conflictos, así sea por razones humanitarias. ${ }^{66}$

Otro legislador perredista, el senador Alejandro Encinas dijo que su bancada no avala, en forma alguna, que México intervenga en misiones de la ONU con participación militar, ya que sería una regresión a su tradicional política exterior. "México debe mantenerse como país pacifista y neutral, donde sus fuerzas armadas estén abocadas exclusivamente a garantizar la seguridad e integridad de nuestro territorio" ${ }^{67}$ En tanto, el senador Manuel Bartlett Díaz, del Partido de los Trabajadores, señaló que:

lo dicho por el presidente en la sesión de las Naciones Unidas es absolutamente contrario a los intereses de este país, y en primer lugar, yo diría son dos razones: uno, la Constitución se lo prohíbe; la Constitución le prohíbe llegar a un acuerdo en el Foro Internacional de que México se incorpora a las misiones de paz, ya saben ustedes que siempre las misiones de paz son el disfraz de las misiones de guerra. En consecuencia, la Constitución no lo permite. Segundo, para entender ese principio hay que ver la historia reciente, la que describe el señor secretario, y las características de la Organización Mundial de la ONU [...] No, no podemos permitir que manden a soldados mexicanos, que son el pueblo de México, a dar su sangre, a morir como sucede, y ahí está la lista de todo lo que ha pasado, ya sea en Kosovo, aquí o allá o en el Medio Oriente. ${ }^{68}$

66 Cámara de Diputados, Diario de los Debates, México, año III, primer periodo, 25 de septiembre de 2014, p. 80.

67 Martínez, Fabiola et al., "Respaldan PAN y PRI en el Senado las misiones de paz", La Jornada, México, 26 de septiembre de 2014, p. 19.

68 Intervención de Manuel Bartlett Díaz durante la comparecencia del secretario de Relaciones Exteriores en el Senado. Versión estenográfica de la Sesión Ordinaria de la Cámara de Senadores del 9 de octubre de 2014, disponible en http://www.senado.gob. $m x /$ index.php? ver $=s p \& m n=4 \& s m=1 \& i d=1560$. El senador Bartlett era el secretario de 
Mariano Aguirre, director del Centro Noruego para la Construcción de la Paz señala sobre los países que participan en las misiones que "En general todos ganan prestigio y mejor acceso a puestos de responsabilidad en el sistema de las Naciones Unidas". Aguirre señala que esos países han recibido críticas internas de sectores que consideran a las acciones de sus gobiernos "intervencionistas", "neoimperialistas" o "imperialistas al servicio de Estados Unidos", cuestionamientos que estima "exagerados". ${ }^{69}$

Pues "resulta un tanto contradictorio abstraerse de participar en ciertas actividades de la ONU a causa de una anacrónica interpretación de un principio que, de hecho, además de no ser exclusivo ni originario del marco legal mexicano, también se encuentra contemplado por los organismos internacionales a los cuales nuestro país pertenece". ${ }^{70}$

\section{Otros casos}

Puede mencionarse también como casos de práctica diplomática bajo el nuevo criterio interpretativo de la no intervención al golpe militar de Tailandia o los intentos de abrogación de Ley de Neutralidad para Conservar la Neutralidad del País.

Como ya se mencionó, se condenó en varias ocasiones el golpe de Estado en Honduras (junio de 2009), primero en un comunicado, expresamente lo hizo el embajador mexicano ante Naciones Unidas en sesión de la Asamblea General y, posteriormente, en la Cumbre del Grupo de Río, cuya secretaría pro tempore coincidentemente recaía en México. Esto era impensable en otros tiempos porque, evidentemente, se contraría la Doctrina Estrada. Sin embargo, ahora es diferente:

El Gobierno de México a través de la Secretaría de Relaciones Exteriores reitera su condena el [sic] golpe militar que suspendió el sistema democrático y constitucional en el Reino de Tailandia. México reafirma su convicción sobre la necesaria aplicación de los principios democráticos para encontrar

Gobernación cuando los principios se incorporaron a la Constitución y, por lo tanto, su firma aparece refrendando el decreto respectivo.

69 Appel, Marco, "Mantener la paz, misión casi imposible”, Proceso, México, núm. 1978, 28 de septiembre de 2014.

70 Cuesta Colunga, Antonio de la, op. cit., p. 48. 
una solución pacífica y duradera a la crisis actual. En este sentido formula un llamado a favor del pleno respeto de los derechos humanos. ${ }^{71}$

Adoptando el criterio de gestación de las mutaciones constitucionales, éstas también pueden producirse por la práctica legislativa y no sólo por la práctica política a cargo del Ejecutivo. Así, se ha intentado abrogar la Ley para Conservar la Neutralidad del País, que promovió el presidente Lázaro Cárdenas, en noviembre de 1939, dos meses después del comienzo de la Segunda Guerra Mundial. Por dicha ley se prohíbe el ingreso y permanencia de buques, aeroplanos y submarinos de países beligerantes. Pasó el conflicto y mucho tiempo más, y la ley continúa vigente. Desde 2003, se han presentado varias iniciativas para abrogarla: la última de ellas en junio de 2015, de la autoría del senador queretano Enrique Burgos, quien, entre otras cosas, considera que es pertinente que el Poder Legislativo de la Unión, de tiempo en tiempo realice la revisión de los ordenamientos jurídicos en vigor y reflexione sobre la pertinencia de que los mismos continúen vigentes. Si bien no hace mención expresa del principio de no intervención, sino de otros contenidos en la fracción X del artículo 89, sí justifica que no es que el derecho de la neutralidad carezca de sentido, sino que debe apreciarse a la luz de la evolución del derecho de gentes.

El principio de la no intervención había sido una tabla de salvación para la diplomacia mexicana que lo invocaba ante situaciones comprometedoras en las cuales no quería pronunciarse ni tomar partido, pero también había sido un impedimento para un libre actuar de la diplomacia mexicana en ciertos temas donde había tenido que abstenerse de participar en detrimento del papel y prestigio del país en el escenario internacional. Nadie previó que, particularmente, el principio de no intervención mudaría en su interpretación a partir de un nuevo contexto internacional que ha permeado intensamente el actuar doméstico, por ello, no es de extrañar que ahora incluso se considere que "fue un error haber incorporado los principios en la Constitución", que "Hoy el principio de no intervención no se interpreta como la invitación al aislacionismo o como la invitación a la ceguera frente una serie de violaciones a los valores universales que hemos acordado defender", para proponer

71 Comunicado 216, Secretaría de Relaciones Exteriores, México, 23 de mayo de 2014, disponible en http://saladeprensa.sre.gob.mx/index.php/es/comunicados/4180-216. 
que "deberíamos pensar en quitarlos de la Constitución o, en todo caso, abandonar esta sensación de que son una camisa de fuerza". ${ }^{72}$

Ahora bien, si los factores exógenos y endógenos se han modificado, bien podría optarse por la otra forma de enmendar el texto constitucional, es decir, la reforma respectiva. La cuestión no se antoja nada fácil. Se ha establecido que "los costos de remplazar o enmendar constituciones pueden ser menores que los costos de dejar esas estructuras sin cambios", ${ }^{73}$ no es el caso, empezando por la simple cuestión del sentido de las palabras, es decir, al derogarse el principio de no intervención necesariamente deberá entenderse que sí se va a proceder con intervención, lo cual significaría apartarse de instrumentos internacionales suscritos por México y que no han mudado en su texto; mucho más cuando "México es un Estado que se considera paladín de la no intervención por autodesignación". ${ }^{74}$ Juan de Dios Gutiérrez Baylón agrega que "en su enamoramiento cultural por el principio de la no intervención, los mexicanos han llegado a extremos impredecibles, tales como el de autoconvencerse que dicho principio consolidado en el derecho internacional general contemporáneo fuese una aportación propia y casi exclusiva de México a las bases del orden jurídico internacional". ${ }^{75}$

Gutiérrez Baylón predijo que "la historia seguirá y México se adaptará a las nuevas semánticas de la no intervención. Ni a priori ni a posteriori es posible pretender que un Estado cumpla con una doctrina bajo criterios químicamente puros". ${ }^{76}$ Pensamos que ese momento ha llegado y que la acepción que contuvo el principio de no intervención, de forma general en la época posrevolucionaria, pero sobre todo, en el contexto de la Guerra Fría ha sido superada y, en este sentido, al dársele una nueva interpretación a dicho principio contenido en la fracción X del artículo 89, puede considerarse que ha generado una mutación constitucional, puesto que aún con "la tendencia de permanecer con un contenido inalterado y en forma completa no se opone a la necesidad del cambio requerido por la variación histórica

72 Intervención del subsecretario para Asuntos Multilaterales y Derechos Humanos de la SRE, Juan Manuel Robledo Verduzco, en el foro "Política exterior de México a debate", convocado por el senador Víctor Hermosillo y Celada el 8 de octubre de 2014. Transcripción a partir de video disponible en https://www.youtube.com/watch? $v=m D H h j g V b X 1 o$.

73 Negretto, Gabriel L., Making Constitutions. Presidents, Parties and Institutional Choice in Latin America, Nueva York, Cambridge University Press, 2013, p. 45.

74 Gutiérrez Baylón, Juan de Dios, op. cit., p. 79.

75 Ibidem, p. 81.

76 Ibidem, p. 87. 
de las circunstancias ni a la consecuente actualización de los contenidos superiores del ordenamiento". ${ }^{77}$

Con diligencia debe considerarse que la mutación no implica necesariamente carta abierta para poder inmiscuirse en asuntos de otros Estados; cierto es que libera al Estado mexicano de las limitantes que doctrinalmente implicaba y de los argumentos de los tradicionalistas de la diplomacia nacional, y le pone en condiciones de no autocensurarse en sus esfuerzos por destacar en el escenario internacional, pero como bien decía César Sepúlveda: "En cualquier caso que se decida que la regla de no intervención merece excepciones, deben examinarse, a la luz del derecho, el propósito de la intervención, los medios empleados, la proporción entre el fin y los medios y la autoridad de quien la emprende y dejar margen para la satisfacción de las responsabilidades sobre su origen y consecuencias". ${ }^{78}$

\section{CONCLUSIONES}

El fenómeno de la mutación constitucional es una constante en la vida de los Estados, y ocurre porque la significación de la Constitución no es dada de antemano, ya que depende del contexto en el cual es concretizado. ${ }^{79}$ En este sentido, las mutaciones obedecen a una perspectiva histórica del cambio jurídico, en adaptar la Constitución a las nuevas realidades, está de manifiesto la idea de acoplar la realidad jurídica normativa y el incesante cambio político. No se pretende que las mutaciones desvirtúen el principio de la estabilidad del texto, por el contrario se busca que éste mantenga vigencia y sea real. ${ }^{80}$

La doctrina ha reconocido que una manifestación de la mutación constitucional es por vía de la práctica política, es decir, tiene lugar por la introducción en la vida política de ciertas prácticas contrarias a lo establecido en la Constitución sin que exista procedimiento jurídico alguno para evitar tal

77 Sentencia C-588/09 de la Corte Constitucional de Colombia, Bogotá, 27 de agosto de 2009, disponible en http://www.corteconstitucional.gov.co/relatoria/2009/C-588-09. htm.

78 Sepúlveda, César, op. cit., p. 27.

79 Sant'ana Pedra, Adriano, "Mutación constitucional y concreción normativa: cómo la estructura de la norma se relaciona con los cambios informales de la Constitución", Estudios Constitucionales, Talca, año 10, núm. 2, 2012, p. 387.

80 Trajtman Robles, Lucciola, op. cit., p. 112. 
incumplimiento ${ }^{81} \mathrm{Y}$ en ocasiones sea conveniente, necesaria o apremiante la adopción de nuevos criterios. En un sistema democrático, su validez requeriría de la ausencia de un manifiesto rechazo de los poderes estatales y de la opinión pública.

Empero, el principio de no intervención, no se confunda, no ha perdido su vigencia. Sigue siendo un imperativo no inmiscuirse en los asuntos internos de otros Estados, pero su criterio interpretativo no es el mismo que tuvo en el contexto de la llamada Guerra Fría. Ahora existe una noción muy aceptada de que asume atenuantes sobre todo si se trata de la protección de derechos humanos y de la promoción de la estabilidad democrática. En este sentido, este criterio aplica para México que ahora no puede invocar el principio para abstraerse de tomar ciertas posiciones. Hoy, México no debe autocensurarse para denunciar violaciones de derechos humanos, dentro y fuera del entorno del Consejo respectivo de las Naciones Unidas ni tampoco debe permanecer pasmado ante los quebrantamientos indebidos de la democracia en otros países. La Doctrina Estrada que tanto lustre dio a la diplomacia mexicana, merece ya un sitial de honor en el archivo histórico diplomático.

La otra solución, es decir, la reforma a la Constitución en este rubro particular no es una tarea prudente ni fácil. Implica costos políticos internos y hasta externos. Sólo intentarlo dará lugar a un alud de críticas, pues la simple lógica indica que si no se es partidario de la no intervención, se es a la inversa y ello generará múltiples interpretaciones.

Justamente la iniciativa presidencial para incorporar los principios de política exterior a la Constitución, en la exposición de motivos, premonitoriamente señalaba "la norma constitucional debe de converger con las necesidades de un pueblo y habrá de ir ajustándose a las transformaciones que experimentan las sociedades, naciones". ${ }^{82}$ Como se ha señalado:

Esos principios, luego, no son estáticos, evolucionan conforme a la dinámica de la sociedad internacional. Sí, en efecto, somos un sistema, si uno concibe al orden internacional como un sistema y al derecho internacional como un sistema, evoluciona como cualquier sistema jurídico, en función de una serie de prioridades del ente que le da sustento [...] los principios deben actua-

81 García Cuadrado, Antonio, op. cit., p. 78.

82 Senado de la República, Diario de los Debates, 9 de noviembre de 1987, p. 9. 
lizarse conforme a los intereses y conforme a la forma en que la sociedad internacional los ha interpretado. ${ }^{83}$

"Pero aún ese principio de no intervención, restringido, limitado, puro, no asume en nuestros días un carácter absoluto. Cede, en todo o en parte, en materia de derechos humanos. También parece ceder cada vez más respecto de la pretensión de la comunidad internacional de preservar el sistema democrático como forma de gobierno de los estados". ${ }^{84}$

Con toda razón don César Sepúlveda argumentaba: "no se oculta que el desafío para regir jurídicamente el fenómeno dual intervención/no intervención es de magnas proporciones, pero es preciso el esfuerzo de intentarlo". ${ }^{85}$

\section{FUENTES}

ACEPRENSA, "Interpretación evolutiva" frente a mutación constitucional, Madrid, Fundación Casatejada, 16 de noviembre de 2012, disponible en https://www.aceprensa.com/articles/interpretacion-evolutiva-frentemutacion-constitucional/.

APPEL, Marco, "Mantener la paz, misión casi imposible", Proceso, México, núm. 1978, 28 de septiembre de 2014.

BENÍTEZ R., Vicente F., "Legitimidad democrática y constitucional de las modificaciones implícitas a la Constitución por parte de la jurisprudencia constitucional en Colombia", Vniversitas, Bogotá, núm. 122, enerojunio de 2011.

Cámara de Diputados, Diario de los Debates, México, núm. 47, miércoles 23 de diciembre de 1987.

, Diario de los Debates, México, año III, primer periodo, 25 de septiembre de 2014.

CARPIZO, Jorge, "La reforma constitucional en México. Procedimiento y realidad", Boletín Mexicano de Derecho Comparado, México, UNAM, Instituto de Investigaciones Jurídicas, año XLIV, núm. 131, mayo-agosto de 2011.

\footnotetext{
83 Gómez-Robledo Verduzco, Juan Manuel, op. cit.

84 Tempesta, Guillermo, op. cit.

85 Sepúlveda, César, op. cit., p. 27.
} 
"Comentan el rompimiento de México con Nicaragua", El Informador, Guadalajara, 22 de mayo de 1979.

Comunicado 024/2014, Secretaría de Hacienda y Crédito Público, México, 25 de marzo de 2014, disponible en http://www.shcp.gob.mx/Biblio teca_noticias_home/comunicado_024_2014.pdf.

Comunicado 216, Secretaría de Relaciones Exteriores, México, 23 de mayo de 2014, disponible en http://saladeprensa.sre.gob.mx/index.php/ es/comunicados/4180-216.

Cuesta Colunga, Antonio de la, "El principio de no intervención en la negativa de México a participar en operaciones de mantenimiento de la paz de Naciones Unidas: una justificación anacrónica”, Documento de Trabajo 209, México, Fundación Rafael Hernández Preciado, octubre de 2005.

Decreto por el que se reforma la fracción X del artículo 89 de la Constitución Política de los Estados Unidos Mexicanos, Diario Oficial de la Federación, México, 11 de mayo de 1988.

EstradA, Genaro, Obras completas, México, Siglo Veintiuno Editores, 1988 , t. II.

GARCÍA CUADRADO, Antonio M., El ordenamiento constitucional. Un enfoque histórico y formal de la teoría de la Constitución y de las fuentes del derecho, Alicante, Club Universitarios, 2002.

GuTIÉRREZ BAYLÓN, Juan de Dios, "La no intervención”, en RABASA, Emilio O., Los siete principios básicos de la política exterior de México, México, UNAM, 2005.

HERRERA LeÓn, Fabián, "El apoyo de México al triunfo de la revolución sandinista: su interés y uso políticos", Anuario Colombiano de Historia Social y de la Cultura, Bogotá, Universidad Nacional de Colombia, vol. 38, núm. 1, enero-junio de 2011.

"Inconsecuencia histórica no romper con Nicaragua", El Informador, Guadalajara, 25 de mayo de 1979.

Intervención de la embajadora Yanerit Morgan Sotomayor durante el debate de la Asamblea General relativo al Informe del Consejo de Derechos Humanos sobre la situación en Siria, 13 de febrero de 2013, disponible en http://mision.sre.gob.mx/onu/images/D12FEB13D01.pdf.

Intervención de Manuel Bartlett Díaz durante la comparecencia del secretario de Relaciones Exteriores en el Senado. Versión estenográfica de la 
Sesión Ordinaria de la Cámara de Senadores del 9 de octubre de 2014, disponible en $h t t p: / / w w w . s e n a d o . g o b . m x /$ index.php? ver $=s p \& m n=4 \& s m=$ $1 \& i d=1560$.

Intervención del presidente Enrique Peña Nieto, en el Segmento de Alto Nivel del Debate General de la Asamblea General de Naciones Unidas (26 de septiembre de 2014), disponible en http://www.presidencia. gob.mx/articulos-prensa/intervencion-del-presidente-de-los-estadosunidos-mexicanos-licenciado-enrique-pena-nieto-en-el-segmento-dealto-nivel-del-debate-general-de-la-asamblea-general-de-nacionesunidas/.

Intervención del subsecretario para Asuntos Multilaterales y Derechos $\mathrm{Hu}$ manos de la SRE, Juan Manuel Robledo Verduzco, en el foro "Política exterior de México a debate", convocado por el senador Víctor Hermosillo y Celada el 8 de octubre de 2014. Transcripción a partir de video disponible en https://www.youtube.com/watch? $v=m D H h j g V b X 1 o$.

KELSEN, Hans, Teoría general del derecho y del Estado, México, UNAM, 1988.

MARTínEZ, Fabiola et al., "Respaldan PAN y PRI en el Senado las misiones de paz", La Jornada, México, 26 de septiembre de 2014.

"México lamenta los acontecimientos en Beijing: SRE", El Informador, Guadalajara, 7 de junio de 1989.

"México no es intervencionista: Jorge Castañeda", El Informador, Guadalajara, 2 de septiembre de 1981.

"México rompe sus relaciones con Nicaragua", El Informador, Guadalajara, 21 de mayo de 1979.

Negretto, Gabriel L., Making Constitutions. Presidents, Parties and Institutional Choice in Latin America, Nueva York, Cambridge University Press, 2013.

OJeda Revah, Mario, México y la Guerra Civil Española, Madrid, Turner Publicaciones, 2005.

Organización de Estados Americanos, Carta Democrática Interamericana. Documentos e interpretaciones, Washington, Organización de Estados Americanos, 2003.

Plan Nacional de Desarrollo 2013-2018, Gobierno de la República, disponible en http://pnd.gob.mx/wp-content/uploads/2013/05/PND.pdf. 
"Preocupa a 9 países el pronunciamiento franco-mexicano", El Informador, Guadalajara, jueves 3 de septiembre de 1981.

RABASA, Emilio O. (coord.), Los siete principios fundamentales de la política exterior de México, México, Partido Revolucionario Institucional, 1993.

— Los siete principios básicos de la politica exterior de México, México, UNAM, 2005.

Resolución 17 del Comité Jurídico Interamericano del 19 de agosto de 2000, en Organización de Estados Americanos, Carta Democrática Interamericana. Documentos e Interpretaciones, Washington, 2003.

Resolución 2131 (XX) de la Asamblea General de las Naciones Unidas, A/RES/20/2131, 21 de diciembre de 1965, disponible en $h t t p: / / w w w$. un.org/es/comun/docs/?symbol=A/RES/2131(XX).

SÁNCHEZ URRUTIA, Ana Victoria, "Mutación constitucional y fuerza normativa de la Constitución. Una aproximación al origen del concepto", Revista Española de Derecho Constitucional, Madrid, año 20, núm. 58, enero-abril de 2000.

SANT'ANA PEDRA, Adriano, "Mutación constitucional y concreción normativa: cómo la estructura de la norma se relaciona con los cambios informales de la Constitución", Estudios Constitucionales, Talca, año 10, núm. 2, 2012.

Secretaría de Relaciones Exteriores, Política exterior de México. 175 años de historia, México, SRE, 1985, t. I.

Senado de la República, Diario de los Debates, México, 9 de noviembre de 1987.

Sentencia C-588/09 de la Corte Constitucional de Colombia, Bogotá, 27 de agosto de 2009, disponible en http://www.corteconstitucional.gov. co/relatoria/2009/C-588-09.htm.

SEPÚlVEDA AMOR, Bernardo, "No intervención y derecho de injerencia: el imperio o la decadencia de la soberanía”, en SEARA VÁZQUEZ, Modesto (comp.), Las Naciones Unidas a los cincuenta años, México, FCE, 1995.

, "Política exterior y orden constitucional: los fundamentos de una política de Estado", en RABASA, Emilio O., Los siete principios básicos de la política exterior de México, México, UNAM, 2005. 
SEPÚlVEDA, César, "La no intervención como norma legal internacional. Sus alcances", en RABASA, Emilio O. (coord.), Los siete principios fundamentales de la política exterior de México, México, Partido Revolucionario Institucional, 1993.

SIERra, Manuel J., Derecho internacional público, México, Porrúa, 1963. Silva, José Afonso da, "Mutaciones constitucionales", Cuestiones Constitucionales. Revista Mexicana de Derecho Constitucional, México, núm. 1, julio-diciembre de 1999, disponible en http://biblio.juridicas. unam.mx/revista/pdf/CuestionesConstitucionales/1/tes/tes 1.pdf.

STERn, Klaus, Derecho del Estado de la República Federal Alemana, Madrid, Centro de Estudios Constitucionales, 1987.

TEMPESTA, Guillermo, "Nuevas avenidas al principio de no intervención: la injerencia humanitaria y la intervención democrática", Revista de Relaciones Internacionales, La Plata, Universidad Nacional de La Plata, vol. 8, núm. 16, 1999, disponible en http://revistas.unlp.edu.ar/RRII-IRI/ article/view/1756/1646.

TRAJTMAn RoBles, Lucciola, "Derecho vivo y mutación constitucional", Revista Jurídica Docentia et Investigatio, Lima, Facultad de Derecho y Ciencia Política de la Universidad Nacional Mayor de San Marcos, vol. 9, núm. 1, 2007.

Uribe ArZate, Enrique y Correa Esquivel, Grisel Alejandra, "Mutaciones constitucionales y la problemática de su control en el Estado constitucional", Revista de Derecho, Barranquilla, Universidad del Norte, núm. 38, 2012.

Wong Meraz, Víctor Alejandro, Constitución mexicana. Reforma y mutación, México, Porrúa, 2010.

Fecha de recepción: 5 de agosto de 2015.

Fecha de dictamen: 5 de septiembre de 2015. 